\title{
Idosos dependentes de cuidadores
}

A primeira edição da Revista Ciência \& Saúde Coletiva de 2021 (26.1) dedica-se a uma das categorias mais esquecidas de brasileiros: as pessoas idosas que perderam sua autonomia e precisam de cuidados de terceiros. Os artigos se debruçam sobre a díade idoso/cuidador. Ou melhor, cuidadora, porque mais de $90 \%$ dos que assistem aos que estão nessa etapa da vida e nesta condição, no Brasil e no mundo, são mulheres. São elas que cumprem a sublime e difícil missão de cuidar, a mais importante da vida humana, segundo Heidegger ${ }^{1}$, embora tão desvalorizada como mostra o relatório da $\mathrm{Oxfam}^{2}$ apresentado no Fórum Econômico Mundial.

A novidade demográfica mais importante no mundo neste momento é o aumento expressivo da longevidade. No Brasil, a contagem da população de dezembro em 2019 mostra que já há no país mais de 24.100 milhões de pessoas acima de 60 anos. E o aumento inédito dos que estão acima de 80 anos se tornou um fato irreversível, sendo esse o grupo mais vulnerável socialmente e do ponto de vista da saúde ${ }^{3}$.

Ainda que a maioria dos idosos brasileiros seja saudável, um percentual não desprezível chega à velhice necessitando da ajuda de terceiros, seja por razões sociais ou por flagrantes deficiências físicas, osteomusculares ou por adoecimento mental. É com foco nesse grupo, reconhecido como "frágil" ou "dependente", que se apresentam os resultados de uma pesquisa qualitativa realizada em oito capitais do país que ouviu 175 pessoas, sendo 64 idosos, 27 cuidadores formais e 84 cuidadores familiares. O estudo abordou análise da situação, representações, percepções, desejos e propostas dos mais diferentes atores. O foco foi sempre nas experiências e vivências dos cuidadores formais e informais e da pessoa idosa quando essa tinha condições de se expressar. Há também na edição, três artigos que tratam das políticas internacionais sobre o assunto.

Os resultados mostram que esta pesquisa tem muitos pontos em comum com outros estudos nacionais e internacionais. Por exemplo, o trabalho de cuidado é um encargo feminino - embora, excepcionalmente, tenham sido entrevistados filhos e esposos extremamente dedicados. Um ponto que seria curioso se não fosse tão recorrente, é o fato de a cuidadora ser, na maioria das casas brasileiras, ao mesmo tempo, a empregada doméstica.

Os artigos sobre as políticas de Estado dão ênfase à Europa, ao Canadá e aos Estados Unidos. Na Europa, o processo de proteção aos mais longevos, em particular aos que precisam de cuidadores, é tratado como parte da solidariedade social que reúne e implica o Estado, os entes subnacionais, a sociedade, as famílias e a própria pessoa idosa ${ }^{4}$.

O Brasil está num momento de decisões importantes sobre as novas demandas trazidas pelo envelhecimento populacional. Pois, ao lado do bônus demográfico existem consequências importantes que atingem os idosos, particularmente na organização familiar e nas mudanças culturais e de costumes.

A ação do Estado brasileiro na formulação de propostas que beneficiem os idosos dependentes e seus cuidadores é quase inexistente. Aqui a ciência está se movendo mais rápido do que os governos, pois já há muitos artigos de autores nacionais sobre o assunto. $O$ diferencial desta edição é juntar no mesmo espaço, os resultados de uma pesquisa feita em vários lugares do país com o objetivo estratégico de evidenciar a necessidade de ação do Estado e da Sociedade frente a questão tão urgente! Não se pode deixar apenas nas costas das famílias o ônus de cuidar dos idosos que dedicaram sua vida ao país e merecem reconhecimento e gratidão no momento em que precisam de uma mão protetora estendida!

Maria Cecília de Souza Minayo (https://orcid.org/0000-0001-6187-9301) ${ }^{1}$

${ }^{1}$ Pesquisadora Emérita da Fiocruz. Rio de Janeiro RJ Brasil.

\section{Referências}

1. Heidegger M. Ser e tempo. São Paulo: Editora Abril; 1980. (Coleção Os Pensadores).

2. Oxfam. Tempo de cuidar. O trabalho de cuidado não remunerado e mal pago e a crise global da desigualdade. [acessado 2020 Out 16]. https://rdstation-static.s3.amazonaws.com/cms/files/115321/1579272776200120_Tempo_de_Cuidar_PT-BR_sumario_executivo.pdf

3. Kalache A. Respondendo à revolução da longevidade. Cien Saude Colet 2014; 19(8):3307.

4. Minayo MCS. O imperativo de cuidar da pessoa idosa dependente. Cien Saude Colet 2019; 24(1):247-252. 